\title{
THE EFFECT OF TWO DIFFERENT ANTIOXIDANTS ON THE SHEAR BOND STRENGTH OF RESIN BONDED GLASS CERAMICS TO BLEACHED ENAMEL
}

\author{
Mohamed Mohey Eldin Mohamed*
}

\begin{abstract}
Aim of the work: The aim of this study was to evaluate the effect of antioxidant agents and delayed bonding on the shear bond strength (SBS) of glass ceramic veneers bonded to the bleached enamel.

Materials \& Methods: A total number of sixty extracted maxillary central incisors with intact labial enamel were collected and randomly divided to six groups of ten teeth each. Ten teeth were remain without bleaching and the remaining fifty teeth were bleached using $35 \%$ hydrogen peroxide, (SDI Polaoffice tooth whitening system ). Sixty lithium disilicate glass ceramic discs of $4 \mathrm{~mm}$ diameter and $5 \mathrm{~mm}$ height were fabricated from IPS e.max Press and divided to six groups of ten discs each. Group I glass ceramic discs bonded to the unbleached enamel surface. Group II glass ceramic discs immediately bonded the bleached enamel after bleaching procedure without antioxidant. Group III glass ceramic discs immediately bonded to the bleached enamel after $10 \%$ ascorbic acid antioxidant application to the bleached enamel. Group IV glass ceramic discs immediately bonded to the bleached enamel after $20 \%$ ascorbic acid antioxidant application to the bleached enamel. Group V glass ceramic discs immediately bonded to the bleached enamel after $2 \%$ green tea antioxidant application to the bleached enamel. Group VI glass ceramic discs bonded to the bleached enamel after 2 weeks waiting period. The tested specimens, were tested for shear bond strength using a universal testing machine at a crosshead speed of $0.5 \mathrm{~mm} / \mathrm{min}$ until failure. The failure load was then recorded and statistically analyzed.
\end{abstract}

Results: Analysis of the mean SBS between all groups it was found that the highest mean SBS for the control group CG of $30.22 \pm 0.92 \mathrm{MPa}$ followed by group VI, with a mean of $26.90 \pm 1.27$ $\mathrm{MPa}$ and group V with a mean of $26.0 \pm 1.80 \mathrm{MPa}$ then group III, with a mean of $25.0 \pm 1.60 \mathrm{MPa}$ and group IV with a mean of $18.99 \pm 1.69 \mathrm{MPa}$ the lowest mean fracture loads of $13.25 \pm 0.36 \mathrm{MPa}$ was for group II.

Conclusions : Within the limitations of this study, it was concluded that antioxidant agents neutralize the effect of bleaching agents and considered a viable alternative to delayed waiting period.

KEYWORDS: Antioxidant, Shear bond strength, Bleaching agent.

\footnotetext{
* Lecturer of Fixed Prosthodontics, Delta University For Science and Technology
} 


\section{INTRODUCTION}

In the context of growing aesthetic awareness many procedures have been proposed to remove the surface stains as microabrasion, macroabrasion, bleaching, laminate veneers and porcelain crowns to restore maximum esthetics. ${ }^{(1,2)}$

Tooth bleaching is a well-accepted procedure, for the treatment of intrinsic staining of teeth, that can be performed at home and in the dental office. Among bleaching agents, are the carbamide peroxide and a high concentration of hydrogen peroxide (30-35\%). (3)

The oxygen present in bleaching agents remove some organic matter from the tooth by diffusion without affecting the enamel matrix, leading to tooth whitening. Although bleaching can successfully give a good result, but sometimes the final color may not be clinically accepted in few cases. ${ }^{(4)}$

Consequently after bleaching procedure, additional aesthetic interventions are recommended, as ceramic laminate veneers, to restore the aesthetic deficiencies however many studies reported a reduction in bond strengths of these restorations..$^{(5,6)}$

Laminate veneers (LV) are indicated as minimal invasive treatment option alternative to full coverage crowns. The durable adhesion of laminate veneers is critical for long-term clinical success since retention of the restorations does not rely on mechanical retention principles. ${ }^{(7)}$

Bonding of veneer restorations to tooth structure immediately after bleaching is challenging as the bond strength is reduced after bleaching procedures as a result of the presence of residual peroxide, that inhibit the resin polymerization, consequently decrease the bond strength of composite to bleached enamel. ${ }^{(9,8)}$

Previous studies recommended a waiting period ranged from 24 hours to 4 weeks after bleaching procedures to gain strong bond strength of the veneers which is impossible in many situations. Thus it is necessary to find new techniques to reduce the waiting period after bleaching. ${ }^{(10)}$

Several studies were suggested to solve the clinical problem of the post-bleached compromised bond strength, moreover demonstrated that the reduced bond strength can be improved immediately after bleaching by the use of antioxidants such as sodium ascorbate, ascorbic acid, butylhydroxianisole, catalase, ethanol, acetone, glutathione peroxide, alpha-tocopherol, sodium bicarbonate, grape seed extract (proanthocyanidin) and green tea extract. ${ }^{(11)}$

Ascorbic acid and its sodium salts are potent antioxidants that have the ability to overcome reactive free radicals of the bleaching agent safely. ${ }^{(12)}$

Increase in bond strength of ceramic veneer to the bleached enamel surface after application of antioxidant can reverse the reduction in bond strength, and may be considered an alternative to the delayed bonding procedure..$^{(13,14)}$

Green tea is a natural product, with an extended shelf life which can be used after bleaching procedure and investigated by several studies. Green tea possesses a potent antioxidant activity that is several times higher than that of vitamins $\mathrm{C}$ and $\mathrm{E} .{ }^{(15)}$

The aim of this study was to evaluate the effect of antioxidant agents and delayed bonding on the shear bond strength (SBS) of glass ceramic veneers bonded to the bleached enamel.

The hypothesis was that the antioxidant has a little effect in improvement of the shear bond strength of indirect restorations to the bleached enamel

\section{MATERIALS AND METHODS}

\section{Materials}

IPS e-max press material, a Luting resin cements, and bleaching agent were used in this study.

A total number of sixty extracted maxillary central incisors with intact labial enamel were 
collected from the Oral Surgery Department at the Faculty of Dentistry, Alexandria University.

The teeth were examined to exclude those with surface cracks and developmental anomalies. Hypoplasia, hypocalcification, and caries on labial surface .

Teeth were cleaned and washed under running tap water. The roots were separated from the crowns using a high speed diamond stone under constant water cooling at the cement-enamel junction and the crowns were embedded in an auto polymerizing acrylic resin block using customized copper mold of dimensions (15 X $20 \mathrm{~mm}$ ), The labial surfaces were placed facing upwards and were flattened using sandpaper disc at low speed under running water.

\section{Methods}

\section{Teeth grouping}

The teeth were randomly divided to six groups of ten teeth each. Ten teeth were left without bleaching and the remaining fifty teeth were bleached using $35 \%$ hydrogen peroxide, (SDI Polaoffice tooth whitening system) and divided into five groups.

\section{Bleaching of enamel}

The polaoffice powder was mixed with hydrogen peroxide liquid by small brush and about 1-2 mm thick layer of gel was applied on the surface of the enamel and left for 15 minutes. Then the gel was removed from the teeth by suction and rinsed with water spray.

\section{Glass ceramic discs fabrication}

Sixty lithium disilicate glass ceramic discs of $4 \mathrm{~mm}$ diameter and $5 \mathrm{~mm}$ height were fabricated from IPS e.max Press (IvoclarVivadent. Benderestrasse 29494 Schann, Liechtenstein, Switzerland). Ceramic specimens were prepared using a specially designed copper mold consisting of the following parts.

\section{1- A copper rectangular base $12 \mathrm{~cm} \mathrm{x} 4 \mathrm{~cm}$.}

2- Two split rectangular plats $5 \mathrm{~mm}$ in height fit on each other on the top of the copper base both split plates incorporate four identical cylindrical split molds of $4 \mathrm{~mm}$ in diameter each. Both split plates were fixed to each other and to the copper base by six screws.

The split mold was paint with separating medium, (IPS Ceramic Separating Liquid, Ivoclar Vivadent AG, Schaan, Liechtenstein) filled with molten wax and after the wax disc became hard the split mold was disassembled then the wax was adjusted, sprued, invested by IPS Press VEST Speed Investment ma $\neg$ terial (IPS Press VEST Speed-Ivoclar vivadent, Schaan Liechtenstein) and pressed from IPS e- max ingot in Press furnace - Programat EP 3000. A digital caliper was used to verify the discs measurements.

\section{Specimens preparation}

Group I, unbleached enamel surfaces (control group).

Teeth specimens were not bleached and the glass ceramic discs were bonded to the treated enamel surfaces as follow.

\section{Pre-treatment of the enamel surface}

Phosphoric acid gel (37\%) was applied to the enamel surface with a disposable syringe tip, for20 seconds. All etchant gel was removed with a vigorous water spray for at least 10 seconds then dried with oil free compressed air for 10 seconds, subsequently, bond was applied and gently agitated for at least 10 seconds and light cured for 20 seconds using a light curing (LED) unit (Bluephase, Ivoclar Vivadent Benderestrasse 29494 Schann, Liechtenstein, Switzerland.

\section{Discs surface treatment and resin cementation}

The discs were etched using 5\% hydrofluoric acid (IvoclarVivadent. Benderestrasse 29494 
Schann, Liechtenstein, Switzerland) for 20 seconds then rinsed off by water then a silane coupling agent, Monobond Plus was applied for 60 seconds then air dried with oil free compressed air. A choice 2 veneer light cured resin cement (Bisco Inc. Schaumburg, IL 60193 U.S.A.) was used to cement the discs to the unbleached labial enamel surface under a custom made load of $2 \mathrm{Kg}$.

Specimens were cured for 3 seconds and the excess cement was remove by scaler then cured for 40 seconds using a light curing (LED) unit (Bluephase, Ivoclar Vivadent Benderestrasse 29494 Schann, Liechtenstein, Switzerland).

\section{Group II, Immediate bonding after bleaching without antioxidant}

The glass ceramic discs were bonded to the enamel surface immediately bonded after bleaching without antioxidant agent application as previously mentioned in group I.

\section{Group III Immediate bonding after bleaching, with10\% ascorbic acid antioxidant}

Teeth specimens were bleached using 35\% hydrogen peroxide, and an antioxidant agent of $10 \%$ ascorbic acid (Faculty of Pharmacy, Alexandria University, Egypt) was then applied to the teeth specimens immediately following bleaching using a disposable brush. The Ascorbic acid was left for 15 minutes then rinsed with water spray for 30 seconds and dried with oil free compressed air.

The glass ceramic discs were then bonded to the enamel surface as previously mentioned.

\section{Group IV Immediate bonding after bleaching, with $20 \%$ ascorbic acid antioxidant}

Teeth specimens were bleached using 35\% hydrogen peroxide, and an antioxidant agent of $20 \%$ ascorbic acid was then applied to the specimens immediately following bleaching using a disposable brush. The Ascorbic acid was left for 15 minutes then rinsed with water spray for 30 seconds and dried with oil free compressed air.
The glass ceramic discs were then bonded to the enamel surface as previously mentioned.

\section{Group V Immediate bonding after bleaching, with $2 \%$ green tea extract antioxidant}

After bleaching procedure was completed $2 \%$ green tea extract antioxidant solution was prepared from $300 \mathrm{mg}$ of green tea extract ${ }^{(4)}$ tablet, (Arab company for pharmaceutical and medicinal plant MEPACO-MEDIFOOD Enshas - sharkeya EGYPT) dissolved in $15 \mathrm{ml}$ of distilled water then applied to the enamel surface and left for 15 minutes then rinsed with water spray for 30 seconds and dried with oil free compressed air.

The treated glass ceramic discs were then bonded to the enamel surface as previously mentioned.

\section{Group VI delayed bonding}

Specimens were bleached using 35\% hydrogen peroxide then placed in artificial saliva in a glass container for 14 days. ${ }^{(16)}$. The artificial saliva solution was changed twice daily during the 14-days time period. The Specimens were removed from artificial saliva and the enamel surfaces were rinsed with water spray dried with oil free air for 30 seconds. The treated glass ceramic discs were then bonded to the enamel surface as previously mentioned.

\section{Specimens Thermal Cycling}

The thermal cycling was done using a custom made machine (Dental Biomaterial Department, Alexandria University). Thermal cycles were 1200 cycles between $5 \mathrm{C}^{\circ} 55 / \mathrm{C}^{\circ}$ water baths with a dwell time of 2 minutes. The thermal cycles parameters were represented one year of oral simulation. ${ }^{(17,18)}$ The specimens were placed in special container that was fixed to a cord circulating around two metal wheels controlled by a motor drive. The container with specimens was allowed to pass through each tank with 2 minutes dwell time. The dwell time represented the amount of time the specimens were 
immersed in particular bath temperature. A counter was attached to the cord to count the number of cycles.

\section{Shear bond strength test}

After Thermal Cycling the tested specimens, were tested for shear bond strength using a Universal Testing Machine (Comten Industries Inc., Florida, USA). The load of the universal testing machine was applied parallel to the long axis of the specimen's surface close to the bonded area, at a crosshead speed of $0.5 \mathrm{~mm} / \mathrm{min}$ until failure.

The failure load was then recorded and statistically analyzed. Shear bond strength (B) values was calculated according to the following equation. ${ }^{(19)}$

$\mathrm{B}=\mathrm{F} \times \mathrm{S}-1$

Where:

B: Shear bond strength in MPa

F: The load in $\mathrm{N}$

$\mathrm{S}$ : The bonded area of the disc in $\mathrm{mm} 2$

$\mathrm{S}=\pi \mathrm{r} 2$

Where:

$\mathrm{S}$ : The bonded area of the disc in $\mathrm{mm} 2$

$\pi: 3.14159$

$\mathrm{r}$ : Radius of the disc in $\mathrm{mm}$

\section{Stereomicroscope test}

After the shear bond strength testing, all the specimens were examined using a stereomicroscope (Olympus SZ-CTV, Japan) and linked digital camera (Panasonic WV-CP 230/ G, Japan) at 20X magnification.

\section{Failure mode}

Adhesive: failure at the enamel-cement interface.

Cohesive: failure in the enamel alone or the resin cement alone.
Mixed: a combination of adhesive and cohesive failures.

\section{RESULTS}

Data were fed to the computer using IBM SPSS software package version 20.0. Quantitative data were described using mean and standard deviation for normally distributed data. For normally distributed data, comparison between more than two population were analyzed F-test (ANOVA) to be used.

Significance test results are quoted as two-tailed probabilities. Significance of the obtained results was judged at the $5 \%$ level.

Analysis of the mean SBS between all groups it was found that the highest mean SBS for the control group CG of $30.22 \pm 0.92 \mathrm{MPa}$ followed by group VI, with a mean of $26.90 \pm 1.27 \mathrm{MPa}$ and group $\mathrm{V}$ with a mean of $26.0 \pm 1.80 \mathrm{MPa}$ then group III, with a mean of $25.0 \pm 1.60 \mathrm{MPa}$ and group IV with a mean of $18.99 \pm 1.69 \mathrm{MPa}$ the lowest mean of $13.25 \pm$ $0.36 \mathrm{MPa}$ was for group II.

Analysis of the SBS of the 6 group by using ANOVA (F) test, it was found that there was a significant difference in SBS between the 6 groups, on comparing the control group with other groups, it was found that there was a significant difference between control and group II, III, IV and V, with high SBS in control group while group VI show insignificant difference with control. Analysis of the SBS between group II and IV it was found that there was no significant difference. On comparing group III and IV, it was found that there was a significant difference with high SBS values in group III. Comparison between group III and V show no significant difference. Comparison between group IV and V show significant difference with high SBS values in group $\mathrm{V}$.

\section{Stereomicroscope examination results}

The shear bond strength results of all the specimens using a stereomicroscope (Olympus SZCTV, Japan) at 20X magnification. Group I revealed 
that adhesive failure in one specimen (10\%), 5 specimens cohesive failure $(50 \%)$ (4 specimens within the enamel surface and one specimen within the resin cement) and 4 specimens (40\%) mixed failure. Group II revealed 8 specimens adhesive failure between the resin cement and enamel surface ( $80 \%$ of specimens), two specimens (20\%) mixed failure and no cohesive failure. Group III revealed that 3 specimens adhesive failure $(30 \%)$ between the resin cement and enamel surface, 2 specimens $(20 \%)$ cohesive failure within the resin cement and 5 specimens (50\%) mixed failure. Group IV revealed that 5 specimens adhesive failure $(50 \%)$ between the resin cement and enamel surface, 2 specimens (20\%) cohesive failure within the resin cement and
3 specimens (30\%) mixed failure. Group V revealed that 2 specimens adhesive failure (20\%), between the resin cement and enamel surface, 2 specimens $(20 \%)$ cohesive failure within the resin cement and 6 specimens (60\%) mixed failure. Group VI revealed that 2 specimens adhesive failure $(20 \%)$ between the resin cement and enamel surface, 3 specimens $(30 \%)$ cohesive failure within the resin cement and 5 specimens (50\%) mixed failure. Fig (2)

The numbers and percent of different types of bonding failure for each group according to stereomicroscopic imaging are summarized in table 2.

TABLE (1) Means and slandered deviation of the tested groups.

\begin{tabular}{|c|c|c|c|c|c|c|c|c|}
\hline $\begin{array}{l}\text { Shear bond } \\
\text { strength }\end{array}$ & $\begin{array}{c}\text { Group I } \\
\text { (CG) }\end{array}$ & $\begin{array}{l}\text { Group II } \\
\text { Immediate } \\
\text { bond }\end{array}$ & $\begin{array}{c}\text { Group III } \\
10 \% \text { ascorbic } \\
\text { acid }\end{array}$ & $\begin{array}{c}\text { Group IV } \\
20 \% \text { ascorbic } \\
\text { acid }\end{array}$ & $\begin{array}{l}\text { Group V } \\
2 \% \text { green } \\
\text { tea extract }\end{array}$ & $\begin{array}{c}\text { Group VI } \\
\text { delayed } \\
\text { bonding }\end{array}$ & $\mathrm{F}$ & $\mathrm{P}$ \\
\hline Min- & 29.30 & 11.61 & 23.40 & 17.30 & 24.30 & 25.30 & \multirow{6}{*}{22.1} & \multirow{6}{*}{$0.001 *$} \\
\hline Max & 31.14 & 15.52 & 26.60 & 20.68 & 27.10 & 28.20 & & \\
\hline Mean & 30.22 & 13.25 & 25.0 & 18.99 & 26.0 & 26.90 & & \\
\hline$\pm \mathrm{SD}$ & 0.92 & 0.36 & 1.60 & 1.69 & 1.80 & 1.27 & & \\
\hline Median & 30.22 & 13.2 & 25.0 & 18.99 & 26.0 & 26.40 & & \\
\hline All \# control & & $0.001 *$ & $0.046^{*}$ & $0.001 *$ & $0.048 *$ & 0.062 & & \\
\hline II \# IV & \multicolumn{6}{|c|}{0.105 N.S. } & & \\
\hline III \# IV & \multicolumn{6}{|c|}{$0.0021 *$} & & \\
\hline III\#V & \multicolumn{6}{|c|}{0.652} & & \\
\hline IV\#V & \multicolumn{6}{|c|}{$0.013 *$} & & \\
\hline
\end{tabular}

*: Statistically significant at $p \leq 0.05$.

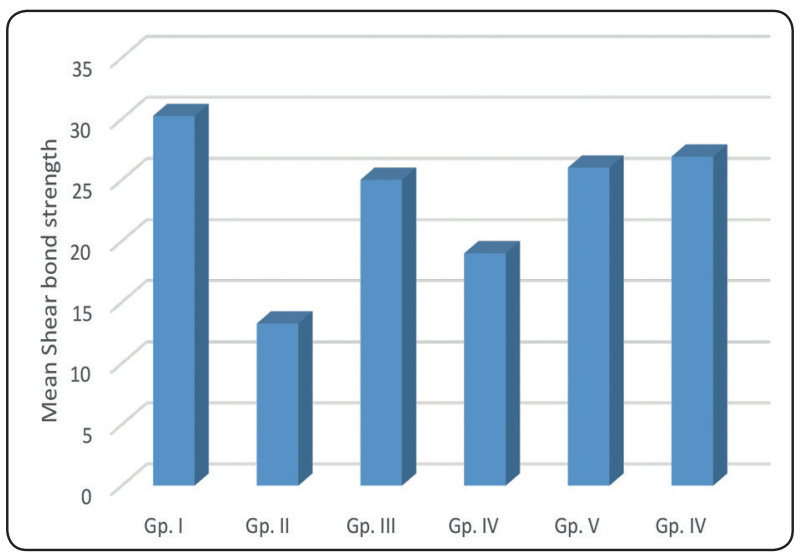

Fig (1) Comparison between SBS in different groups 


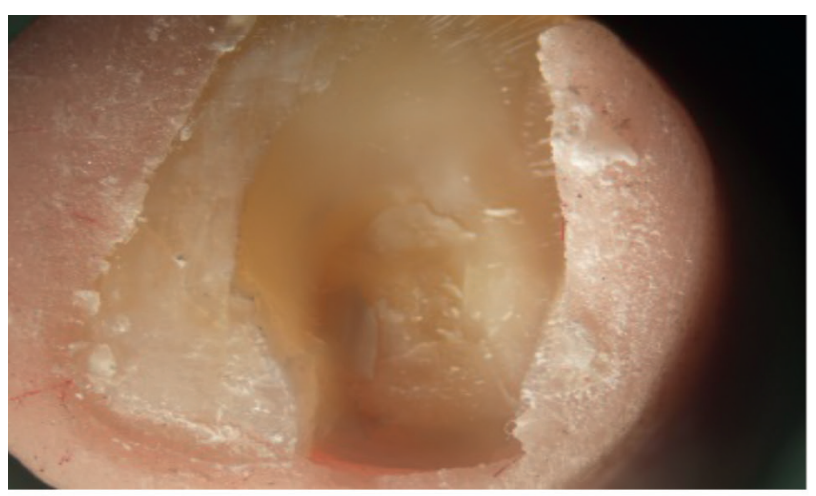

Cohesive failure within the tooth structure in Group I (control group).

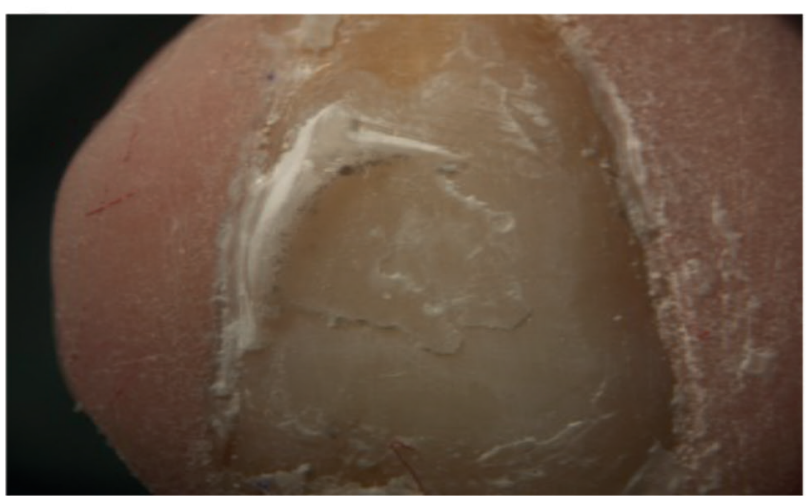

Cohesive failure within resin cement III

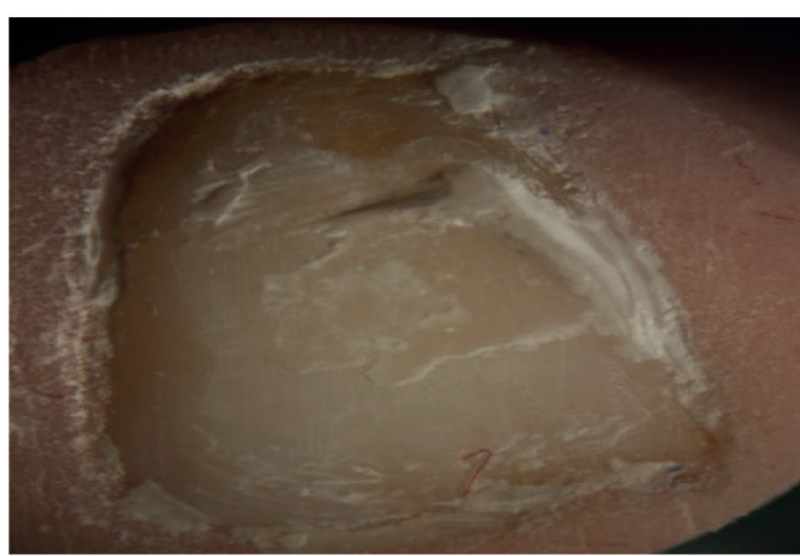

Mixed failure in Group V

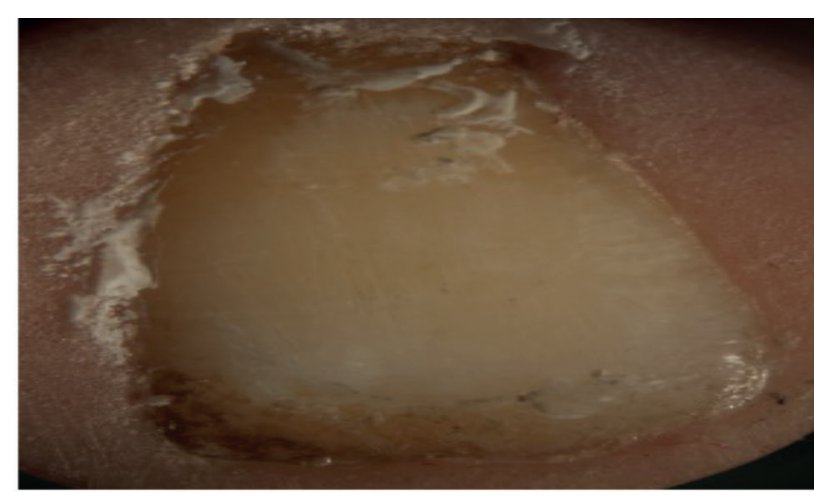

Adhesive failure in Group II

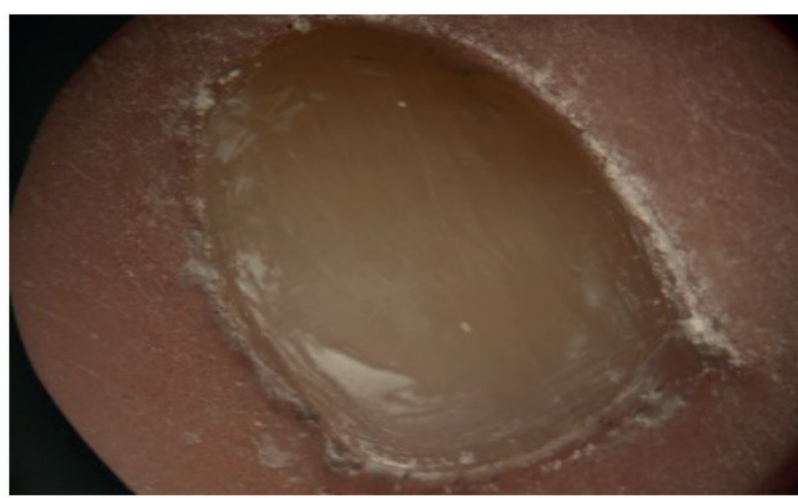

Adhesive failure in Group IV

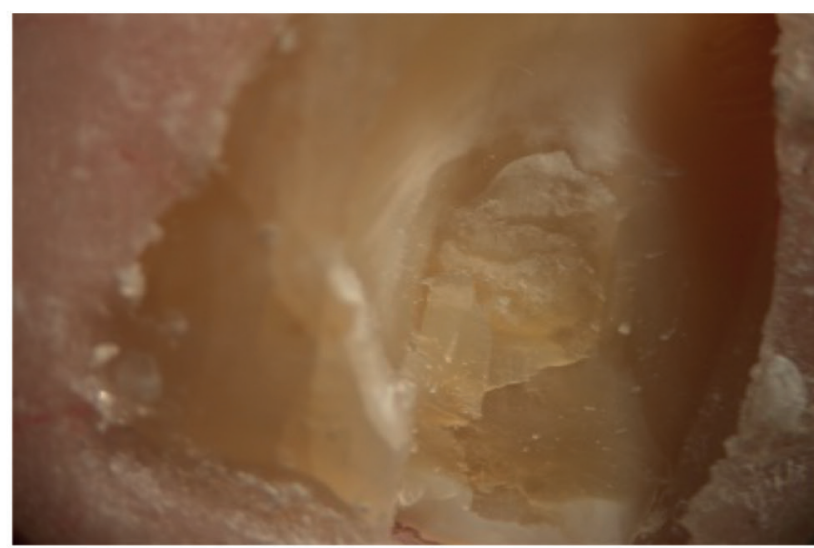

Mixed failure in Group VI

Fig (2): Failure modes of tested groups .

TABLE (2): Comparison between the failure modes of tested groups in percent.

\begin{tabular}{|c|c|c|c|c|c|c|}
\hline \multirow{2}{*}{ Groups of failure } & \multicolumn{2}{|c|}{ Adhesive $(\mathrm{n}=10)$} & \multicolumn{2}{c|}{ Cohesive $(\mathrm{n}=10)$} & \multicolumn{2}{c|}{ Mixed (n=10) } \\
\cline { 2 - 7 } & No & $\%$ & No & $\%$ & No & $\%$ \\
\hline Group I & 1 & $10 \%$ & 5 & $50 \%$ & 4 & $40 \%$ \\
\hline GroupII & 8 & $80 \%$ & 0 & $0 \%$ & 2 & $20 \%$ \\
\hline GroupIII & 3 & $30 \%$ & 2 & $20 \%$ & 5 & $50 \%$ \\
\hline GroupIV & 5 & $50 \%$ & 2 & $20 \%$ & 3 & $30 \%$ \\
\hline GroupV & 2 & $20 \%$ & 2 & $20 \%$ & 6 & $60 \%$ \\
\hline GroupVI & 2 & $20 \%$ & 3 & $30 \%$ & 5 & $50 \%$ \\
\hline
\end{tabular}




\section{DISCUSSION}

The initial bond strength to enamel surface after bleaching is important to be investigated as patients may require an additional aesthetic rehabilitation. ${ }^{(20)}$

Previous studies showed that the bond strengths of indirect restorations to tooth structure were decreased when the tooth was bleached with carbamide peroxide or hydrogen peroxide.Many reports suggested a waiting period ranged from 1 day to 3 weeks are mandatory to proceed with an adhesive procedure. ${ }^{(21)}$

Clinical success of bonded restorations depend on adequate adhesion to tooth surface and any disturbance of adhesion of such restorations can affect its longevity and its failure. ${ }^{(10)}$

Immediate bonding of indirect restorations after bleaching procedures decreases the bond strength as a result of a delayed release of oxygen that could interfere with resin infiltration into the etched enamel or inhibit polymerization of resins. If the oxygen-rich surface layer of enamel is removed, the bond strength of resin to enamel returns back near to the normal values. ${ }^{(22)}$

The use of antioxidants to eliminate the residual oxygen in the enamel structure immediately after bleaching to enable the bonding procedure, was studied.

Antioxidants surface treatment showed improvement in bond strength whereas others showed conflicting results in improving the bond strength values. ${ }^{(24,23)}$

This study was conducted to evaluate the effect of two types of antioxidant, ascorbic acid and green tea extract, on the shear bond strength of glass ceramics to the bleached enamel surface and compare this bond strength value with the immediate and delayed bond strength.

The result of this current study showed that treatment with $2 \%$ green tea extract (Group V) has a significantly higher bond strength compared with group IV (20\% ascorbic acid) and there was no significant difference with group III (10\%ascorbic acid). This could be attributed to the hydroxyl groups present in its structure that bind and neutralize the free $\mathrm{O}_{2}$ radicals.

The $2 \%$ green tea extract has the same antioxidant activity as $10 \%$ ascorbic acid and both antioxidants had more powerful antioxidant activity than $20 \%$ ascorbic acid.

Sharafeddin $\mathrm{Fa} .{ }^{(25)}$ et al concluded that, using green tea extract as antioxidant had no significant effects on the SBS of resin composite to enamel bleached with $15 \%$ carbamide peroxide gel but it had significant increasing effect on the shear bond strength of resin composite to enamel bleached with38\% hydrogen peroxide gel, they related this result to the less amount of residual oxygen molecules produce by carbamide peroxide gel than hydrogen peroxide and they supposed that the effect of the antioxidant on SBS increase as the bleaching agent concentration increased. These results were in agreement with the result of the current study.

In another study they reported that the application of both sodium ascorbate, and green tea on enamel surface bleached with $38 \%$ hydrogen peroxide can neutralize the effect of residual oxygen on the bleached enamel and consequently increase the SBS of resin composite. This result was in agreement with the result of the current study. ${ }^{(26)}$

Hwang JY, ${ }^{(27)}$ et al showed that treatment with $2 \%$ green tea extract increases bond strength significantly to the bleached enamel and attributed this result to that the green tea is a polyphenols antioxidant potential so has hydroxyl groups structure, which bind and neutralize the free radicals, the result of this study is in-agreement with the result of this current study.

Ascorbic acid and its salt sodium ascorbate are antioxidant that allows the free-radical polymerization of the adhesive resin by restoring the altered redox potential of the oxidized substrate thus reversing the compromised bonding in same 
time may increase the bond strength as a result of its etching potential. ${ }^{(28)}$

This study showed the positive effects of $10 \%$ ascorbic acid solution as an antioxidant on the bonding capacity to enamel surface bleached with $35 \%$ hydrogen peroxide and reported a significant increase in shear bond strength in the group that received the antioxidant for 10 minutes. On the other hand $20 \%$ ascorbic acid did not increase the shear bond strength significantly, this indicated that increase in concentration of ascorbic acid has no effect in shear bond strength of resin to the bleached enamel.

Several studies reported that the application of antioxidant on the bleached enamel before bonding procedures can completely neutralizes the deleterious effects of bleaching and increases the bond strength significantly. Anoharan M.(29) studied the effect of $10 \%$ sodium ascorbate gel as antioxidant on the bond strength of the resin to bleached enamel and concluded that antioxidants neutralizes the effects of bleaching and increases the bond strength to bleached enamel significantly. This result was in agreement with the result of this study.

Subramonian $\mathrm{R}$ et al. ${ }^{(30)}$ evaluated the effect of $10 \%$ sodium ascorbate, on the shear bond strength of composite resin to bleached enamel and observed that the use of antioxidants effectively reversed the reduced bond strength of bleached enamel. This result coincide with the result of this study.

Muraguchi K, et al. ${ }^{(31)}$ showed that $10 \%$ ascorbic acid has a low $\mathrm{pH}$ and when used for 1 or 10 minutes, can create micromechanical retention on bleached enamel which consequently increases the bond strength which is in agreement with this study.

Kunt GE, et al. ${ }^{(32)}$ reported that antioxidant agents can increase the bond strength of resin to the immediately bleached enamel after 10 minutes application of $10 \%$ ascorbic acid, which is reasonable time for clinical use.
Lai et al. ${ }^{(23)}$ immersed the bleached specimens in $10 \%$ sodium ascorbate solution for $3 \mathrm{~h}$ and concluded that sodium ascorbate treatment appeared to restore the reduced bond strength of composite to the bleached enamel samples after certain time not less than $3 \mathrm{H}$.

This result did not coincide with the current study, this may be due to the low $\mathrm{pH}$ and etching ability of $10 \%$ ascorbic acid, used in this study, that creates micromechanical retention beside its antioxidant effect on bleached enamel.These two factors are considered the main cause of the increase in SBS.

Another study was done by Silva $\mathbf{J}$ et al. ${ }^{(31)}$ who concluded that the sodium ascorbate was the only antioxidant agent able to totally reverse the bond strength to enamel immediately after bleaching and in the same time delayed bonding for 1 week after bleaching increased the bond strength to bleached enamel, this result is in agreement with the result of this study.

Suneetha R et al. ${ }^{(34)}$ Analyzed the bond strength of composite resin to bleached enamel using a synthetic and herbal antioxidants and showed that the sodium ascorbate antioxidant agent can reverse the bond strength of composite to enamel immediately after bleaching which is in agreement with the result of this study.

The present study, showed that treatment with $10 \%$ of ascorbic acid and $2 \%$ green tea antioxidant solutions have the ability to reverse the value of bond strength as unbleached teeth beside that there is no significant difference in bond strength of resin to bleached enamel treated with ascorbic acid and green tea, and both materials were able to neutralize the negative effect of bleaching agent.

Waiting period time after bleaching is required to restore the bond strength to unbleached level is quite controversial. Although, there are variations among the waiting periods, many studies recommended a delayed period before bonding for 1 week after bleaching by immersion in a remineralized solution to restore the enamel properties and optimal adhesion. ${ }^{(34,35)}$ 
The present study showed that the shear bond strength of group I (unbleached group) is higher than all tested groups with significant difference between the group I and groups II, III, IV,V and insignificant difference with group VI (delayed bonding). The shear bond strength of the antioxidant treated group, control and delayed bonding groups were much higher than the immediate bonding group, with the control being the highest.

In this study, delayed bonding recovered the bond strength of a resin to enamel.

These results were in agreement with Turkun et al. ${ }^{(36)}$ who reported that there were no statistically significant differences in shear bond strength between the delayed bonding and the unbleached enamel surface. This might be due to the possible structural changes on enamel that were repaired during waiting period while teeth were stored in artificial saliva.

Zhao $\mathrm{H}$, et $\mathrm{al}^{(37)}$ explained that the structural alteration of the enamel and the reduction of bond strength in the presence of peroxide related to the replacement of the hydroxyl radicals in the apatite lattice by peroxide ions and produce peroxideapatite and when peroxide ions decompose, it was substituted again by the hydroxyl radicals which inter the apatite lattice, resulting in the elimination of the structural changes caused by the incorporation of peroxide ions.

Khoroushi et al. ${ }^{(38,39)}$ suggested, a certain waiting period is required to allow a gradual elimination of residual oxygen from the bleached surface before adhesive restoration. This may be due to that immersion in water causes dispersion of residual oxygen that remains within the enamel and dentin matrix. Another explanation is that hydrogen peroxide is extremely unstable and may lose its activity after a period of time.

To minimize the effect of bleaching agent, several techniques were studied as pretreatment of bleached enamel with alcohol, the use of adhesives containing organic solvents, or sodium ascorbate antioxidant, and a post-bleaching waiting period ranging from 24 hours to three weeks. ${ }^{(40)} \mathrm{Al}$-Hassani and Al-Shamma $\mathrm{A}^{(41)}$ compared the neutralizing effect of delayed bonding and different antioxidant agents on the microleakage of composite restoration after bleaching with hydrogen peroxide. They concluded that delayed bonding of resin to the bleached teeth up to 14 days was enough to remove of the effect of bleaching also treatment of the bleached teeth with $10 \%$ sodium ascorbate, and $10 \%$ green tea antioxidant solution neutralize the adverse effect of bleaching material. These conclusions were coinciding with the current study.

The hypothesis of this study was rejected because it was found that different antioxidant agents affect the bond strength of enamel immediately after bleaching.

\section{CONCLUSIONS}

Within the limitations of this study, it was concluded that $10 \%$ ascorbic acid and $2 \%$ green tea antioxidant agents effectively neutralize the deleterious effect of bleaching agents and increase the resin bond strength of the glass ceramic to the enamel and considered a viable alternative to delayed waiting period.

\section{REFERENCE}

1. Griffiths CE, Bailey JR, Jarad FD, Youngson CC. An investigation into most effective method of treating stained teeth: An in vitro study. J Dent. 2008; 36: 54-62.

2. Kimyai S, Oskoee SS, Rafighi A, Valizadeh H, Ajami AA,Helali ZN. Comparison of the effect of hydrogel and solution forms of sodium ascorbate on orthodontic bracket-enamel shear bond strength immediately after bleaching: an in vitro study. Indian J Dent Res. 2010;21:54-58.

3. Cavalli V, Arrais CA, Giannini M, Ambrosano GM. Highconcentrated carbamide peroxide bleaching agents effects on enamel surface. J Oral Rehab 2004;31:155-9..

4. Shashibhushan K.K, Manoharan M., Poornima P, V.V. Subba Reddy. Effect of Novel Herbal Products on the Bond Strength of Composite on Bleached Enamel. Int J Dent Med Res 2015;5:20-23 
5. Toko T, Hisamitsu H. Shear bond strength of composite resin to unbleached and bleached human dentin. Asian $\mathrm{J}$ of Aesthetic Dentistry 1993;1:33-6.

6. Titley KC, Torneck CD, Smith DC, Chernecky R, Adibfar A.Scanning electron microscopy observations on thepenetration and structure of resin tags in bleached and unbleached bovine enamel. J Endod 1991;17:72-5.

7. Marco M.M. Gresnigta, Mutlu Özcanb, Marco Carvalhoc, Priscilla Lazaric,Marco S. Cunea, Peywand Razavia, Pascal Magne. Effect of luting agent on the load to failure and accelerated-fatigue resistance of lithium disilicate laminate veneers Marco. Dent Mater 2017; 33:1392-1401.

8. Dabas D, Patil AC, Uppin VM. Evaluation of the effect of concentration and duration of application of sodium ascorbate hydrogel on the bond strength of composite resin to bleached enamel. J Conserv Dent. 2011; 14:356-60.

9. Sung EC, Chan SM, Mito R, Caputo AA. Effect of carbamide peroxide bleaching on the shear bond strength of composite to dental bonding agent enhanced enamel. J Prosthet Dent1999;82:595-9

10. Unlu N, Cobankara FK, Ozer F. Effect of elapsed time following bleaching on the shear bond strength of composite resin to enamel. J Biomed Mater Res. 2007; 84: 363-368.

11. Garcia EJ, Oldoni TL, Alencar SM, Reis A, Loguercio AD, Grande RH. Antioxidant activity by DPPH assay of potential solutions to be applied on bleached teeth. Braz Dent J. 2012; 23:22-7.

12. Torres CR, Koga AF, Borges AB. The effects of anti oxidant agents as neutralizers of bleaching agents on enamel bond strength. Braz J Oral Sci 2006;5:971-6.

13. Ram Suneetha, S Pavithra, John Thomas, G Swapna Priya Nanga, Aseem Shiromany5, Amit Shivrayan6 An In Vitro Comparative Study of Shear Bond Strength of Composite Resin to Bleached Enamel using Synthetic and Herbal Antioxidants. International Oral Health J 2014; 6:77-81

14. Kaya AD, Turkun M. Reversal of dentin bonding to bleached teeth. Oper Dent. 2003;28:825-9.

15. Kimyai S, Valizadeh $\mathrm{H}$. The effect of hydrogel and solution of sodium ascorbate on bond strength in bleached enamel. J Oper Dent. 2006;31:496-9.

16. Berger SB, De Souza Carreira RP, Guiraldo RD, et al.Can green tea be used to reverse compromised bondstrength after bleaching? Eur J Oral Sci. 2013;121:377-381
17. Shirakura A., Lee H., Alessandro G., Ercoli C., and Changyong F.The influence of veneering porcelain thickness of all-ceramic and metal ceramic crowns on failure resistance after cyclic loading. J Prosthet Dent 2009; 101:119-127.

18. Stappert Ch., Ozden U.,Gerds Th.,and Strub J. Longevity and failure load of ceramic veneers with different preparation designs after exposure to masticatory simulation. J Prosthet Dent 2005;94:132-9.

19. Sasaki RT, Florio FM, Basting RT. Effect of $10 \%$ sodium ascorbate and $10 \%$ alpha-tocopherol in different formulations on the shear bond strength of enamel anddentin submitted to a home-use bleaching treatment.J Oper Dent. 2009;34:746-752.

20. Ozelin A, Ricardo DanilGuiraldo, Rodrigo Varella de Carvalho, Murilo Baena Lopes, Sandrine Bittencourt Berger Effects of green tea application time on bond strength after enamel bleaching. Brazilian Dental Journal 2014;25: 399-403.

21. Hikita K, Van Meerbeek B, De Munck J, Ikeda T, Van Landuyt K, Maida T, Lambrechts P, Peumans M. Bonding effectiveness of adhesive luting agents to enamel and dentin. Dent Mater 2007;23:71-80.

22. Cvitko E, Denehy GE, Swift EJ Jr, Pires JA. Bond strength of composite resin to enamel bleached with carbamide peroxide. J Esthet Dent. 1991; 3:100-2.

23. Lai SC, Mak YF, Cheung GS, Osorio R, Toledano M, Carvalho RM, Tay FR, Pashley DH. Reversal of compromised bonding to oxidized etched dentin. Dent Res J. 2001;80:1919-24.

24. Borges A, Rodrigues JR, Borgues AL, Marsilio AL. The influence of bleaching agents on enamel bond strength of a composite resin according to the storage time. Rev Odontal UNESP 2007;36:77-83.

25. Sharafeddin Fa, Farshad Fb, Azarian Bc, Afshari Ad Effect of Green Tea Extract as Antioxidant on Shear Bond Strength of Resin Composite to in-Office and HomeBleached Enamel. Journal of Dental Biomaterials. 2016; 3:269-275.

26. Sharafeddin F, Motamedi M, Modiri SH. Effect of Immediate Application of Pomegranate Peel, Grape Seed and Green Tea Extracts on Composite Shear Bond Strength of In-Office Bleached Enamel. Res J Biol Sci. 2013;8:83-87.

27. Hwang JY, Choi SC, Park JH, Kang SW. The use of green tea extract as a storage medium for the avulsed tooth. J Endod. 2011; 37:962-7. 
28. Hyo-Jin Whang,Dong-Hoon Shin. Effects of applying antioxidants on bond strength of bleached bovine dentin. Restor Dent Endod J. 2015;40:37-43.

29. Manoharan M, Shashibhushan KK, Poornima P, Naik SN, Patil D, Shruthi AS. Effect of newer antioxidants on the bond strength of composite on bleached enamel. J Indian Soc Pedod Prev Dent. 2016;34:391-6

30. Rajalekshmy Subramonian, Vijay Mathai, Jeya Balaji Mano Christaine Angelo, and Jotish Ravi .Effect of three different antioxidants on the shear bond strength of composite resin to bleached enamel: An in vitro study. J Conserv Dent. 2015;18:144-148.

31. Muraguchi K, Shigenobu S, Suzuki S, Tanaka T. Improvement of bonding to bleached bovine tooth surfaces by ascorbic acid treatment. Dent Mater J. 2007; 26: 875-881.

32. Kunt GE, Yilmaz N, Sen S, Dede DO. Effect of antioxidant treatment on the shear bond strength of composite resin to bleached enamel. Acta Odontol Scand. 2011; 69: 287-291.

33. Juliane Marcela Guimaraes da Silva, Ana Carolina Botta, Daphne Câmara Barcellos, Clovis Pagani, Carlos Rocha Gomes Torres. Effect of Antioxidant Agents on Bond Strength of Composite to Bleached Enamel with 38\% Hydrogen Peroxide. Materials Research. 2011; 14: 235-238.

34. Ram Suneetha, S Pavithra, John Thomas, G Swapna Priya Nanga, Aseem Shiromany, Amit Shivrayan. An In Vitro Comparative Study of Shear Bond Strength of Compos- ite Resin to Bleached Enamel using Synthetic and Herbal Antioxidants. J International Oral Health 2014; 6:77-81.

35. Bülent GökçM.Erhan Çömlekoğlu, Birgül Özpinar, Murat Türkü, Ayşegü Demirbas, Kaya Effect of antioxidant treatment on bond strength of a luting resin to bleached enamel. J Dent 2008; 36:78 0-785.

36. Türkün M, Kaya AD. Effect of $10 \%$ sodium ascorbate on the shear bond strength of composite resin to bleached bovine enamel. J Oral Rehabil. 2004; 31:1184-91

37. Zhao H, Li X, Wang J, Qu S, Weng J. Zhang. Characterization of peroxide ions in hydroxyl apatite lattice. Journal of Biomedical Materials Research 2000;52:157-63.

38. Khoroushi M, T Saneie Post-bleaching application of an antioxidant on dentin bond strength of three dental adhesives. Dent Res J 2012;9: 46-53.

39. Khoroushi M, A Feiz, M Ebadi Influence of intermediary filling material on microleakage of intracoronally bleached and restored teeth. Dent Res J 2009 ; 6: 17-22.

40. Ferraz LN, Oliveira Albm, Grigoletto M, and Botta AC. Methods for Reversing the Bond Strength to Bleached Enamel: A Literature Review. JSM Dent J. 2018;6:1105.

41. Ameer A Al-Hassani1 and Abdulla MW Al-Shamma. Effect of Delayed Bonding and Different Antioxidants on Composite Restoration Microleakage of Internally Bleached Teeth. Adv Dent \& Oral Health J. 2018;6:1-6. 